\title{
Research on Influence of WeChat on College Students' Behavior
}

\author{
Dong Yang, Jun-Peng Zhang \\ Department of Thermal Engineering, Shandong Jianzhu University, Jinan, China \\ E-mail: zhangjunpeng36@sina.com
}

\begin{abstract}
WeChat soon get the attention and actively participate of college students as a new way of interpersonal communication. When WeChat is rapidly developing, users tend to be younger, high degree of education. Students encountered many challenges and opportunities in interpersonal communication by WeChat as the main application. Therefore, college students' use of WeChat is a noteworthy attention. Based on the relevant literature, We analyzed why now WeChat is able to become the main use of mobile phone chat software and expounds the influence of the function of WeChat on the interpersonal communication of college students from the psychology.
\end{abstract}

Keywords-WeChat; College Students; Behavior; psycholo gy

\section{INTRODUCTION}

The network era change rapidly emerged; there are new forms of social forms such as QQ, homepage, blog, micro-blog and so on. With the diversification and versatility of the social network, the communication between college students is no longer limited to phone calls and text messages, but has more and more new choices. And WeChat came into being, powerful, rapid envelopment.

According to over the years the "Chinese Internet development statistics report" ${ }^{1}$ published by China Internet Information Center, both age and occupation distribution shows that, in China's Internet users, college students have become the main force on the Internet. And with the development of network information technology, campus network construction has been developed a lot in Colleges and Universities. It provides a favorable network conditions for the college students. As a convenient means of information access and communication platform, the network has been deeply integrated into the daily life of college students.

The most way of interpersonal communication between college students is network. So, college students should follow the trend and learn how to use WeChat to communicate. Scanning the street is a very interesting new feature. When the user of the mobile phone takes pictures of a nearby building, micro channel will automatically identify the location of the name. Just imagine, when the user scan to a cinemain the street, which indicates that the release of the film, movie tickets, the remaining seats; scan to a restaurant, WeChat immediately shows the specialty of this restaurant, the level of per capita consumption even buy packages. If WeChat will be the feature of commercial, advertising revenue space will be very amazing ${ }^{2}$.

\section{II..INTERNAL MOTIVATION}

WeChat expand the new space for interpersonal communication and communication of college students. Because of the anonymity and virtual micro channel, college students can be bold to pour out their inner secrets, and increase thire chance to opening heart to communicate with people. WeChat is used for free, and it only consumes some of the flow.1M traffic can send about 1000 text messages, 1000 second voice information, about 1 minutes of video information. WeChat integrated a variety of mobile phone plug, such as QQ mailbox assistant, QQ offline assistant, communication security assistant, etc. So there are more people know the powerful software features of the phone. Compared with other mobile phone software, WeChat function is more comprehensive, practical, features. So WeChat is able to become a necessary artifact for college students' travel and interpersonal communication. Thangks to WeChat's powerful function, college students depend on it more and more. These reasons prompted Tencent Inc to continue to innovate and update it. College students are a special group, and the university campus is a special region. College students are one of the first contact and the first to accept the group of WeChat. And WeChat communication practice has become one of the basic practical activities of their social interaction3. As a result, WeChat is bound to have an important impact on their interpersonal communication.

\section{III. .MIND OF RIVALRY}

The interpersonal relationship of college students is simple and pure. The reason for this is that there is no purpose of communication between them. Their motivation for communication is very simple. Because of same hobbies or same dream, they become good friends to each other.WeChat version 5 provide a game platform for college students to spend their spare time. These games which can be seen in the latest version of the mobile phone QQ game center, such as tiantianlianmeng, attract a large number of young college students. You can get a WeChat friend relationship chain, or QQ friends' relationship chain, docking Tencent mobile gaming platform. You also can invite friends to play together, to see who is on the list of NO.1.Young people; most of them have the heart of 
competitive. And students are young people, too. They also have the heart of competitive. In order to compete for their game rankings NO.1, they spend a certain amount of time in each game. Everyone figure out to show off, and compare themselves to others after the game over. In fact, I believe that everyone may have a heart, and even vanity.

\section{HERD MENTALITY}

Now the WeChat is very popular in university campus. It may be a "herd mentality" of college students; a form of expression4.The diversification of the way of communication of WeChat has greatly enriched the way of communication of college students, and offered unlimited choice space. From another point of view," sea memory confidant, Tianya Zorpia" this sentence is no longer just a romantic poet, more substantive connotation after WeChat appearing. For college students, WeChat has successfully integrated the advantages of the existing means of communication, breaking the limitations of a single communication tool, and will soon be accepted by college students. Most of modern Chinese college students are in the golden period of 22 to 18 years of age, whose ability to accept new things are stronger. And a lot of them driven by curiosity and have a strong demand for friends. At the same time, college students accepting higher education and having a certain degree of education, the most active in the main force of Chinese Internet users, will undoubtedly become one of the main users of WeChat group.Modern college students have used WeChat accounts for $73 \%$ which is is very large base5,6.So that the use of WeChat has been a fashion.

\section{V..PSYCHOLOGICAL ADVENTURES}

College Students' curiosity and sense of community let WeChat pop up. At the same time, it has become a popular culture. The new function is interesting, but also attracted many curious students attention7, such as voice communication, LBS, yaoyiyao, saoyisao. Because of their curiosity, promoting their understanding of this product, $21.01 \%$ of college students choose WeChat. A popular saying in modern society:' do you have WeChat?"Did you "hit the plane" today?'Due to a derivative meaning of 'hit the aircraft', many college students heard this name would like to explore it by psychological Adventures.' Space physical proximity is easy to cause the psychological closeness. Many people's curiosity is very strong, especially around strangers. And WeChat's near people function just to meet the people of this psychological Adventure. This is one of the reasons why WeChat can become a human contact.' said associate Professor Liu Wei, Department of psychology, Shanghai Normal University. College Students' daily contacts are variety, whether with new friends or old friends, relatives or strangers. WeChat, a simple and effective, a wide range of communication tools,provide convenience for college students.

\section{VI. .THE SENSE OF IDENTITY}

WeChat, a high-end network communication tool, since it was introduced, enter the University campus in a rapid trend. WeChat through its most unique voice chat, which delivered a message of affection, reduces the plain text derived strange feeling and breaks the limit of distance with the help of network transmission. It can be said that there is no media have more form of transmitted message than WeChat in so many campus media. Signature broadcast information in voice to be used in WeChat, and traditional text information, picture information is also. In short, WeChat conforms to the trend of the development of new media, which is bound to open a new era of information dissemination in the university.

\section{VII. .DISCUSSION}

WeChat, a new type of communication and entertainment tool, can meet the students' positive attempt and pursuit of high-tech products. Its own function is also able to meet the needs of college students on social entertainment and communications, and the favor of college students is understandable. However, confront WeChat, we should have a certain self-control which control the time of using WeChat's and more can not indulge in WeChat's social and entertainment functions and affect our learning and life8.We suggest that college students should have an objective and rational understanding of the things that like WeChat. We should use its communication, making friends, entertainment and other functions to make our life more convenient and exciting, rather than let WeChat dominate our lives.

\section{ACKNOWLEDGEMENTS}

The author would like to thank colleagues from the Adolescent Subjects for the financial support.

\section{REFERENCES}

[1] Liu Tong, "Research on the Influence of Wechat to the Interpersonal Communication of College students" .Master's Thesis, East China Normal University, 2014.

[2] Li Lie, "A Study of Innovating Approach to Managing Students by Means of New Communicative means", Journal of Zunyi Normal College, vol.14, no.6, pp. 78-80, 2012.

[3] Yang Min, "Research on the Challenges and Countermeasures of the Ideological and Political Education for College Students by WeChat", Cyberdemocracy, vol.6, pp. 72-76, 2012.

[4] Wen Ruyan, "Research on the Influence of Wechat on College students' Interpersonal Communication", .Master's Thesis, Lanzhou University, 2014.

[5] Tang Haiyin, "the Status of the College Students Use Wechat--Based on the 'Use and Satsfaction' Perspective", Master's Thesis, Tianjin Normal University, 2015. 
[6] Zhao Xin, "A Study of Influence of Wachat to Undergraduates in Ideological and Polotical Education and the Countermeasures", .Master's Thesis, Wuhan Institute of Technology, 2013.

[7] Wang Xiaoyu, "The usage intention and behavior of
Wechat”.Master's Thesis, Lanzhou University, 2013.

[8] Han Dong, "Analysis of 90s College Students' Characteristics and Educational Management", Journal of Beijing City University, vol.6, pp. 80-84, 2010. 